March - 2007

\title{
The Development of Distributed Learning Techniques in Bhutan and Nepal
}

\author{
Frank Rennie \\ University of the Highlands and Islands Millennium Institute, Scotland \\ Robin Mason \\ Open University UK
}

\begin{abstract}
This paper discusses research and development work currently being conducted with universities in Bhutan and Nepal to design appropriate systems for distance and distributed learning courses among a network of campus sites. Although working from a high level of awareness of pedagogic skills, staff in the region face two significant impediments in the adoption of a more open culture of learning. Firstly, Internet access is improving rapidly, but is still generally too weak and inconsistent to allow any reliance on net-based learning solutions. Secondly, the academic culture is resistant to the recognition of the value of open-learning degrees, with subsequent difficulties in re-designing course materials for a more educationally flexible, student-centred learning environment. Some current pilot initiatives in distributed learning are described. Methods for addressing these two impediments are discussed.
\end{abstract}

Keywords: Distributed education; Nepal; Bhutan; pedagogy

\section{Introduction}

The term 'distributed education' is used in a wide variety of ways to refer to quite different educational practices. The University of the Highlands and Islands Millennium Institute (UHI) is distributed in the sense that it is composed of 15 colleges spread over a very wide geographical area of northern Scotland. Various technologies are used to deliver courses to students so that they do not need to re-locate in order to access higher education. The British Open University can be called distributed in the sense that it too uses technology to deliver courses to students spread over the whole UK and beyond. Online and face-to-face tutorials are held to support students in their study of largely print-based course materials.

Blended learning is another term that is often used to refer to practices similar to distributed education. Blended learning usually implies a combination of online and face-to-face teaching (Sharp, Benfield, Roberts, \& Francis 2006). Distributed education usually implies a separation either in time or space between the teacher and the taught. In any case, what both concepts are addressing is the need for greater flexibility and access to higher education than the traditional campus experience affords (Mason \& Rennie, 2006). 
Both Bhutan and Nepal have a higher education system that could be called distributed, although they differ in the nature of the distributed components. Travel is extremely difficult in both countries due to the mountainous terrain and the lack of infrastructure. Access to secondary education, much less higher education, is a major problem and only a small percentage of the total populations attend university. As the Vice Chancellor of the Royal University of Bhutan (RUB) has commented, a distributed education system suits the geographical situation of Bhutan (Dukpa, 2004).

In this paper we will outline the different distributed systems in Bhutan and Nepal, and describe current uses of technology to provide distributed education. Finally, we will suggest possible options for increasing both access and flexibility in the future.

\section{Context}

Nepal and Bhutan are both small land-locked Asian countries in the foothills of the Himalayas, with India and China as near neighbours. Both are fiercely independent and proud of their traditions and history. Education is a high priority for both as a way out of the poverty trap.

\section{Bhutan}

The Royal University of Bhutan is the only university in Bhutan, having been established in 2003 from a network of nine specialist institutes scattered around the country. It is therefore, distributed in somewhat the same way as UHI, though students of RUB have to re-locate to the college which teaches their chosen subject, whereas students of UHI can study their chosen subject from their local college using various forms of online technology.

There is a wide diversity in the educational development of the RUB institutes, and in the faculties and departments across the university. The National Institute of Traditional Medicine teaches almost entirely through indigenous languages and is based on ancient Tibetan concepts of medicine, whereas the National Institute of Education has many staff members with second degrees from Occidental universities and has adopted many advanced pedagogical approaches that would be familiar to Western academics. English is the language of education from primary school upwards, and is the sole language of higher education. Academic partner colleges in the network specialise in a specific curriculum area, so for example there is an Institute of Management, an Institute of Technology and a Natural Resource Training Institute, all located in different parts of the country. As might be expected in a newly established university in an emergent country, there are many curriculum areas that cannot be addressed, particularly at more advanced levels of study and in areas of high cost resources. A small number of students travel abroad, especially to India, for their undergraduate training. The enthusiasm and commitment to education is high among both staff and students, with a high retention rate and high progression into employment for completing students.

The Internet structure is rudimentary, particularly outwith the capital, and is not consistently reliable enough to permit even a moderate level of technological networking beyond email exchanges. Telephone networks are heavily dependent upon mobile phones, and the radio and television broadcasts have sporadic coverage across the country. Although education is highly valued in Bhutanese society, there are a number of cultural peculiarities that are relevant to the context of the current paper. Firstly, distance or online learning is not common practice in any subject area, and is frequently regarded with suspicion by academic staff, employers, and students 
alike. This should come as no surprise as this was a common attitude in the West until about twenty years ago (and some may say is still prevalent in subject-specific areas). Secondly, the concept of 'critical thinking' so highly regarded by Western academics, is anathema to the traditional Buddhist educational system, and this actively works against the idea of studentcentred learning that values curiosity, rationality, and creative approaches to learning. This contrast between 'traditional' and 'modern' educational thinking is carefully explored by Phuntsho (2000) and we will return to this later. The challenge, therefore, is to continue to nurture a progressive, open educational system in Bhutan, but to do so with respect to the prevalent culture of society, and within the limits of technology that is appropriate to the tasks in hand.

\section{Nepal}

The situation is somewhat different in Nepal, but this difference is only superficial and produces many similar effects. Tribhuvan University is the largest of the six universities in Nepal, accounting for about 95 per cent of the student body. The university is largely based in Kathmandu, although in recent years there has been a rapid growth to include a large number of 'affiliated colleges' some of which are very small and specialised. The majority of these colleges offer management, humanities and/ or education programmes and only a few offer science degrees. The curriculum for all programmes is defined by the central faculty in Kathmandu and delivered primarily by lectures at the different colleges. This is, thus, a different form of distributed education from the practice in Bhutan.

Around 89 per cent of the population of Nepal live in villages, and as one of the poorest economies in Asia, there is a large difference in the standards of living between the urban areas and the rest of the country. Undoubtedly this is a major contributor to the fact that only 2 per cent of the total population receive higher education, and even from this there is a high drop-out rate, as much as 50 per cent (Singh, 2006) largely due to financial constraints. There are further difficulties of educational provision in the inclusion of women, and for different castes/ ethic minorities (Singh, 2006) and also with the social unrest in the rural areas due to ten years of insurrection by Maoist guerrillas.

The curriculum at Tribhuvan University is diverse, and some subject areas, such as engineering, medicine, and education command parity with the best in SE Asia. The teaching methods tend to be very conservative, and there is an emphasis on memorisation, exams, and courses that are not resource intensive (possibly due to ongoing funding difficulties between the university and the state)(Wagley, 2006). Major problem areas are the relevance of completed degrees to employers, the issue of equity/ equality of access to higher education by different sections of society, and the poor retention rate of students (Wagley, 2006). There has been some involvement with distance education techniques in Nepal, largely to do with the training of teachers in rural areas (Thapaliya, 2006) using radio, cassette tapes, and printed materials, but this pilot has been very limited. As with Bhutan, the value of open education degrees is widely suspect by most academics, administrators, and employers (and therefore students too) although the university has recently announced its intention to recognise a second degree obtained by distance/ open learning so long as the first degree is from a 'traditional' route. There is an understanding of the need to move towards the use of distance education methods, and a general commitment to this from the University and from government, but as yet this is solely rhetorical. Internet access is poor to non-existent outwith major urban areas although there is a rapid increase in mobile phone users, and Nepal Telecom seems poised on the cusp of a campaign to roll out wireless and satellite broadband connection, subject to continued funding. 


\section{Current Experiences}

Although distributed learning is in its infancy in both Bhutan and Nepal, there have been a number of pilot initiatives to experiment with more flexible styles of course delivery. The Nepalese have expressed an interest, in principle, to create an Open University of Nepal, based upon existing academic strengths in key areas. The Royal University of Bhutan, on the other hand, is a much newer institution and is conducting a more cautious appraisal of the role of technology to support their form of distributed learning within the university network. In both countries there is a strong tradition of face-to-face teaching, usually with much higher tutorstudent contact hours than would be normal in a western university. There has been a reliance on lectures, in particular, as a teaching medium, a method that has been compounded for both staff and students due to the relative scarcity of sufficient, modern books, journals, and technological assistance through video, DVD, and the Internet.

Teacher education has been a focus of efforts to increase access and flexibility at both universities. In Nepal, the aim has been to provide training for those teachers who have no teaching qualifications, and to offer professional updating for those who wish to continue their studies whilst working. Tribhuvan University started a one year distance-taught B.Ed programme in 2001 using print materials plus some face-to-face workshops. The National Centre for Educational Development is a small flexible education unit within the university that has recent expertise in producing course materials. Instructional programmes have combined radio broadcasts, cassette tapes, and print resources to assist the continued professional development of rural primary teachers. This "Interactive Radio Instruction" (IRI) has enabled some rural teachers to engage effectively with CPD for the first time, and to reduce the demands on attendance at regional assessment and learning centres. There are hopes to extend this pilot, both in its geographical scope and in the range of learning resources (e.g., CD/ DVD might be developed). Despite the fact that the distance taught students performed better on the final examinations than the campus-based students, the acceptance of the distance degree is very low. This is a cultural constraint to the effectiveness of more flexible learning styles in Nepal and Bhutan, and we will come back to this issue later. Tribhuvan University is currently planning to use some distance learning processes in all their programmes as a way of spreading understanding and acceptance of the method. There is a recognised need for the development of academic staff in this area. "As it is not possible to recruit competent human resources in the distance education sector, the only way left is to develop the human resources after they enter into the job" (Thapaliya, 2006, p. 2). An additional opportunity is the need to provide CPD to government officials in the civil service at their work locations throughout Nepal.

A recent phenomenon in Nepal, especially in the Kathmandu Valley, has been the meteoric growth of 'affiliated colleges' that are associated with the university. Most of these 'colleges' are in fact small (some very small) specialist teaching centres that prepare students in a limited number of subject areas (e.g., business management or ICT) and act as feeders for the appropriate university courses that are delivered centrally on a campus in Kathmandu. The presence of so many affiliated colleges throughout Nepal makes it feasible to run face-to-face workshops or offer support and access to technology for many people throughout the country. The rapid proliferation of these colleges does, however, present challenges for quality assurance, consistency in the level of access to learning resources, and the general issues of equivalence of the student learning experience.

Tribhuvan University is also a partner in a network of Asian universities trialling networked videoconferencing, especially for science and technology subjects. A standard videoconference 
'lecture' is delivered to the network of participating Asian universities by a staff specialist, and using Internet relay technology, the class of students at each participating site have a brief opportunity to question the lecturer. This technology, which tends to use teacher-centric lecturing, seems to be more acceptable in Nepal than print-based distance education. Although the technology is very expensive, and therefore restricted to a very elite group of students (a class of about 20 engineering students in the event in which we participated) the similarity of the pedagogy to 'conventional' teaching (i.e., the visual stimuli of a specialist lecturer giving an oral presentation, accompanied by diagrams on a whiteboard, etc.) is less challenging than a more radical pedagogy of independent, student-driven learning. In fact, it could be argued that pedagogy is a major deterrent to the introduction of many forms of distributed education in both Nepal and Bhutan.

Where a belief in the importance of content and in the authority of the teacher as knowledge expert prevails, those forms of distributed education which pass more control to the learner are inherently suspect. The importance of the content prevails over the educational context, and learning styles are conditioned to perpetuate the role of passive learners rather than critical thinkers seeking to apply their acquired knowledge in new ways. This is not just a problem of education in Nepal and Bhutan of course, and will be familiar to educationalists worldwide, but to some extent this regional approach has been accentuated by lack of resources. The studentcentred pedagogy of much Western higher education depends on the availability of books, journals, libraries and online resources. These are very much more restricted in less developed countries and consequently reliance on the teacher and the content knowledge of the expert is understandable. Videoconferencing, using satellites rather than landlines, is an obvious technology for distributing education to remote colleges in Nepal, although this gives rise to a whole set of subsequent problems that are political as well as educational in nature - e.g., the degree of centralised control over course delivery; the level of two-way interaction; priorities over the allocation of expensive equipment and scheduling of its use. In a region where expensive technologies and other learning resources are scarce, there is a strong tendency towards centralisation of control, and this is directly contradictory to the principles of making access to higher education more flexible.

The situation is slightly different in Bhutan, partly due to the scale of the university, party to the short length of time they have had to consolidate the development of the university, and partly due to the geography. The immediate demands for networked teaching technologies are less obvious for Bhutan as the colleges each teach different subjects. There is a wide diversity in the pedagogy and pedagogical sophistication across the RUB, although the range of subject courses and disciplines is much more limited, as would be expected of an embryonic university. Pedagogic approaches range from the very traditional Buddhist style of memorization and oral contact in the Dzongka language of the college of traditional medicine, to the more recognisable western interaction(in English) of the two centres of teacher education. The latter have recently experimented with Moodle as a tool for teaching and learning, and have expressed interest in other forms of open source software solutions. The current opportunities for open access to education are largely restricted to a limited number of specially equipped college campuses as the mountainous terrain does not allow ubiquitous radio coverage; television access is sporadic and growing slowly from a previous period when it was tightly controlled by government (Rapten, 2001; McDonald, 2004); and Internet access outwith a few locations in the capital is largely restricted to a small number of government offices and colleges. In Bhutan, therefore, the introduction of educational technology to facilitate more flexible delivery of higher education, might be at least initially, concentrated on the provision of diversifying the modes of learning for campus-based students so that they can spend less time in the classroom and more in directed private study. Access to course readings via print, CD, audio cassettes, (and the Internet as access 
grows) to supplement class notes and interaction with tutors and peers might be more appropriate in the immediate future for introducing an element of distributed education in Bhutan. There are, however, significant opportunities for the employment of distributed learning methods and resources for the continuous professional development of staff located at the scattered network of colleges, and we will consider this issue in the final section of this paper.

\section{Exploring Potential Solutions}

In both Bhutan and Nepal there are two complementary challenges to the effective adoption of distributed learning techniques, the first being the technical limitations, and the second, the more substantial in our view, being the cultural 'mind shift' that is required. Although there are many similarities between the two countries there are also many differences. Furthermore, while it would be convenient in this paper, it would be wrong for us to lump them together too closely. Consequently we will proceed cautiously in dealing with some general issues, and punctuate this with reference to specific differences where these occur.

\section{Technical challenges}

Despite being formidable, the technical challenges can be dealt with here fairly easily. As we have seen globally, ICT is a very fast-moving subject area, and this produces communications solutions for now that were regarded as distant dreams just a few years ago. We have little doubt that this will also apply to Bhutan and Nepal. Both of these countries have seen the rapid adoption of new technologies where appropriate and affordable - i.e., both have experienced a massive growth in the use of mobile phones in an area where landlines are inconsistently reliable or impossible to deploy. One of the bonus points about being a less-developed nation with a strong motivation to engage in technological change is the ability to learn from the experience of others and leapfrog over their early mistakes. If Bhutan and Nepal continue to concentrate emphasis on appropriate technologies, then there are several immediate options available. It is clear from our work in these areas that for both Bhutan and Nepal there can be some quick wins in achieving a more open, flexible curriculum by focussing initially on the provision of asynchronous learning activities for conventional campus-based students. In the case of Nepal, this could be extended to cover networked provision for students attending a number of the remote campus locations. The roll-out beyond the main Kathmandu campus of the current experimentation in videoconferencing to include a network of key locations throughout Nepal is a good example of this.

Lack of adequate access to up-to-date print resources can be partially addressed by the digitisation of key articles and incorporating these on a CD and/ or a VLE that can be accessed out of class from key institutional locations. The educational advantages of broader bandwidth access to the Internet are the subject of discussion in western educational establishments (Rennie \& Mason, 2005) and even at this stage there are signs that these issues are being considered in different ways for Nepal and Bhutan. For example, although in the early stages of deployment, our discussions with Nepal telecom indicate that broadband access to the Internet is set to have a massive increase in availability, at least in the Kathmandu Valley. Wireless access options are also being planned for urban areas, and the extension of this may be the only realistic option for the more rural locations. This may seem to be rather optimistic, but the rapid adoption in recent years of mobile telephones in preference to static landlines has demonstrated that, when it is appropriate, new technology is capable of providing innovative solutions to the particular difficulties of developing countries. In the case of Nepal there are substantial benefits to be gained by the provision of asynchronous learning materials, including: 
- Reduction in the (currently heavy) conventional teaching load

- Greater consistency of course quality across the university where the same course is taught on multiple sites

- Reduction in duplication and better deployment of human resources

- Better use of scarce learning resources

- Better social inclusion of learners to include the more rural areas.

In Bhutan, the scale of the issue is different, and though both the mountainous terrain and the level of public awareness may be serious constraints to general access to the Internet, there are a number of obvious aspects that require consideration. Technologies that facilitate collaborative working and access to shared resources will be a major advantage for staff development, and in helping to build a corporate culture for the new Royal University of Bhutan. They will also be beneficial in the provision of open and distributed learning opportunities for government staff in local departments throughout the country. Although students in Bhutan currently re-locate to the campus providing the specialist subject that they have selected, the adoption of improved communications and distributed learning techniques may also offer significant opportunities to provide short courses, part-time study, CPD, and new subjects that are delivered on a network basis throughout the national campus network. Such a solution might also go some way towards addressing the concerns, raised by Wangyal (2001) and reported from many other parts of the world, that the dislocation of students for the purposes of study in locations far from home may have a disruptive effect on rural society.

\section{Socio-cultural challenges}

Although the technical challenges are not to be underestimated, our work to date indicates that the cultural shift required to recognise and implement the benefits of open and distributed learning in Nepal and Bhutan is of a much greater order of magnitude. The heavy reliance on an oral tradition, lectures, seminars, and discussion, as the main, or only, means of knowledge transmission is in part a legacy of the monastic tradition (Phuntsho, 2000; Wangyal, 2001) and partly a result of the general scarcity of other media. There is also a contention (as expressed, for instance, in the writings of the latter authors, such as Phuntsho, 2000, p. 100) that there are stereotypical views of 'Western' attitudes to education versus 'Eastern' motivations, the former being typified as largely for personal gain and career choices and the latter being the pursuit of knowledge as self-improvement for its own sake. We would certainly challenge this gross generalisation, but some elements we observed do have a bearing on the uptake of open and distributed learning opportunities. The cultural tradition of great deference to teachers and tutors has placed a premium upon received knowledge, and even though Wangyal (2001, p. 109) notes that "According to traditional values individual self-discipline is considered important for harmonious co-existence," this does not appear to be a strongly motivating force towards greater learner autonomy and the use of multiple media for student-centred learning. This is especially evident in Bhutan, where the Buddhist traditions frequently result in great discomfort with the western notions of 'critical thinking' and 'critical appraisal' as these are (erroneously) conflated with the notion of criticising the teacher or subject expert.

Grow (1991, p. 129) has defined a four-stage self-directed learning model which outlines the elements that are crucial for the effective deployment of successful open and distributed learning courses. The majority of the higher education in Bhutan and Nepal would appear to correspond with "Stage 2." This stage categorises the student as "interested," the teacher being recognised as a motivator or guide, using for example an "inspiring lecture plus guided discussion and goal setting." In Stage 3, the student is "involved," the teacher is a facilitator and uses seminar 
"discussion facilitated by the teacher who participates as [an] equal." If a goal of distributed learning is to produce self-directed, lifelong learners, with more open and flexible access to higher education, then much work remains to be done in both Nepal and Bhutan to create a favourable educational culture. In particular, government, employers, students, and educationalists themselves need to be convinced of the validity and robustness of the Quality Assurance process that governs distributed learning.

Clearly there are issues here of institutional vision and educational leadership. The desire and the requirement to design appropriate solutions for distributed learning in Bhutan and Nepal can substantially benefit from collaboration with trusted external partners. Although the importance of the need for outstanding educational leadership is not only applied to the developing open education models in Bhutan and Nepal (Hitt \& Hartman, 2002) their current situation makes the recognition of good educational leadership much more critical. In both countries, only a very small proportion of the total population receive higher education. There is an urgent need to extend social inclusion to the educational sphere in order that society can address important domestic difficulties in economic, environmental, social, and political matters. The proportion of qualified, local academic staff is an even more elite section of society, so they are simultaneously well placed to provide innovative, far-sighted policies for the structure of open education and disadvantaged in promoting their case in the country as a whole.

Although distributed learning presents an attractive option for 'progressive' educationalists in Nepal and Bhutan, and though scope exists for modest gains in the short and medium term, we are less convinced that sufficient institutional motivation exists for the required curriculum redesign that will facilitate this. In addition to the usual staff concerns that have been common in western colleges and universities relating to the reduction of contact hours, the need for skills training, and possible redundancies due to over-capacity, there is a fundamental leap required in the redesign of assessment instruments. As Hedberg and Lim (2004, p. 203) note, "While curriculum redesign is an important factor to ensure effective e-learning, assessment approaches also need to be considered if effective change is to occur. Curriculum and assessment are interdependent and mutually supportive."

Any consideration of the immediate to mid future of distributed learning in Bhutan and Nepal would predict, at most, cautious progress. Both countries are well placed to take appropriate advantage of new technologies without requiring a replication of the infrastructure or the historical mistakes of the industrialised countries. Progress will be determined less by overcoming technical barriers, and more by accommodating fundamental socio-cultural shifts in attitudes towards education. This needs to be accompanied by the articulation of a clear vision of institutional goals, the provision of resources commensurate with the tasks identified, and by encouraging widespread collaboration throughout the institution and with educated society in general.

\section{Summary}

The following table summarises the similarities and differences in the implementation of distributed learning in Nepal and Bhutan.

\section{Similarities and differences}

- Much of the country consists of remote and mountainous terrain 
- Longevity of the university sector (Nepal 50 years; Bhutan 3 years)

- $\quad$ Consistent challenges to providing up-to-date educational resources

- Basic model of distributed education (Nepal utilises local learning centres; Bhutan requires students to travel to geographically scattered campuses)

\section{Cultural resistance to education at a distance}

Cultural differences in educational tradition (Nepal = Hindu; Bhutan = Buddhist $)$

\section{Poor IT infrastructure over most of the country}

- State of readiness for IT learning solutions (e.g., Nepal experimenting with video links and wireless Internet; Bhutan experimenting with Web-based solutions, but in major institutions only)

- Largely an instructivist mode of tuition (tutor-led)

- Scale of public access to the higher education system

\section{Conclusions}

It is generally acknowledged that introducing technology is far easier than changing pedagogy. This applies to the higher education scene in both Nepal and Bhutan where landline technology is particularly problematic due to the mountainous terrain. Nevertheless, mobile and satellite technology can leapfrog over traditional solutions and offer some 'quick wins' in both countries, as they have in other developing countries. Media such as videoconferencing which do not disturb existing attitudes to teaching and learning are probably going to be the most acceptable in the short term at least.

Bhutan has a stated policy of resisting 'inappropriate' westernisation and to the extent that this is successful, a pedagogy of self-directed learning will probably continue to be resisted. Given their existing system whereby the student travels to the appropriate college, there is less need to develop a truly distributed university. Introducing elements of resource-based and student-centred learning for campus students, however, may be the way forward to taking advantage of the best aspects of flexible learning.

Nepal has the beginnings of a distributed network of colleges and hence may find more drivers to develop the technologies and the pedagogies that lead to distributed learning. However, adding greater flexibility to existing campus courses so that students can work to support their studies as is increasingly common in western universities - may be the most effective starting point in Nepal. Some quick wins can be achieved by focussing initially on the provision of asynchronous learning activities for conventional campus-based students and, in Nepal, by extending the rollout of videoconferencing delivery to student locations outwith Kathmandu. In both countries, the digitisation of key print resources and incorporating these on a CD and/ or a VLE can partially address student access to relevant, up-to-date sources of academic literature. Wireless access may soon offer a realistic option for off-campus access to resources in both urban and some more rural locations. In Bhutan, collaborative Web-based technologies and access to shared resources, even 
though in the medium term these are only available on the major campuses and in government institutions, will offer a major benefit for staff development, and help to build a culture of distributed learning for the new university.

\section{References}

Dukpa, Z. (2004). Message from the Vice Chancellor, Royal University of Bhutan. Natural Resources Training Institute Annual Magazine, 12(2), 5-6.

Grow, G. O. (1991). Teaching learners to be self-directed. Adult Education Quarterly 41(3), 12549.

Hedberg, J. G., \& Lim, C. P. (2004). Charting trends for e-Learning in Asian schools. Distance Education 25(2), 199-213.

Hitt, J. C., \& Hartman, J. L. (2002). Distributed Learning: New challenges and opportunities for institutional leadership. The American Council on Education and Educause. Retrieved October 24, 2006 from: http://www.acenet.edu/bookstore/pdf/distributed-learning/distributed-learning03.pdf

McDonald, R. (2004). Television, Materialism and Culture: An exploration of imported media and its implications for GNH. Journal of Bhutan Studies 11. Retrieved October 24, 2006 from: http://www.bhutanstudies.org.bt/journal/vol11/v11-4.pdf

Mason, R., \& Rennie, F. (2006). Elearning: The Key Concepts. Abingdon, Oxon: Routledge.

Phuntsho, K. (2000). On the two ways of learning in Bhutan. Journal of Bhutan Studies 2(2), 96126. Retrieved October 24, 2006 from:

http://www.bhutanstudies.org.bt/journal/vol2no2/v2n2learning.pdf

Rapten, P. (2001). Mass Media: Its consumption and impact on residents of Thimphu and rural areas. Journal of Bhutan Studies 11(1). Retrieved October 24, 2006 from:

http://www.bhutanstudies.org.bt/journal/vol3no1/v3n1media.pdf

Rennie, F. and Mason, R. (2005). Bits or Baubles: The opportunities for broadband to add value to education and learning. Scottish Affairs 53, 31-47. Retrieved October 24, 2006 from: http://www.lews.uhi.ac.uk/about/research/Bits\%20or\%20Baubles2.pdf

Sharpe, R., Benfield, G., Roberts, G., \& Francis, R. (2006). The Undergraduate Experience of Blended e-Learning: A review of UK literature and practice. A Report to the Higher Education Academy. Retrieved October 24, 2006 from: http://www.heacademy.ac.uk/4884.htm

Singh, M. (2006). Towards a New Paradigm of Higher Education: A reflection on distance education in Tribhuvan University Paper presented to the EU-Asia Seminar on Distributed Learning, Kathmandu, 2-10 March 2006.

Thapaliya, T. P. (2006). Human resource in Distance Education in Nepal. Paper presented to the EU-Asia Seminar on Distributed Learning, Kathmandu, 2-10 March 2006. 
Wagley, M. P. (2006). Higher Education in Nepal Paper presented to the EU-Asia Seminar on Distributed Learning, Kathmandu, 2-10 March 2006.

Wangyal, T. (2001). Ensuring Social Sustainability: Can Bhutan's education system ensure intergenerational transmission of values? Journal of Bhutan Studies 3(1) 106-31. Retrieved October 24, 2006 from: http://www.bhutanstudies.org.bt/journal/vol3no1/v3n1education.pdf 